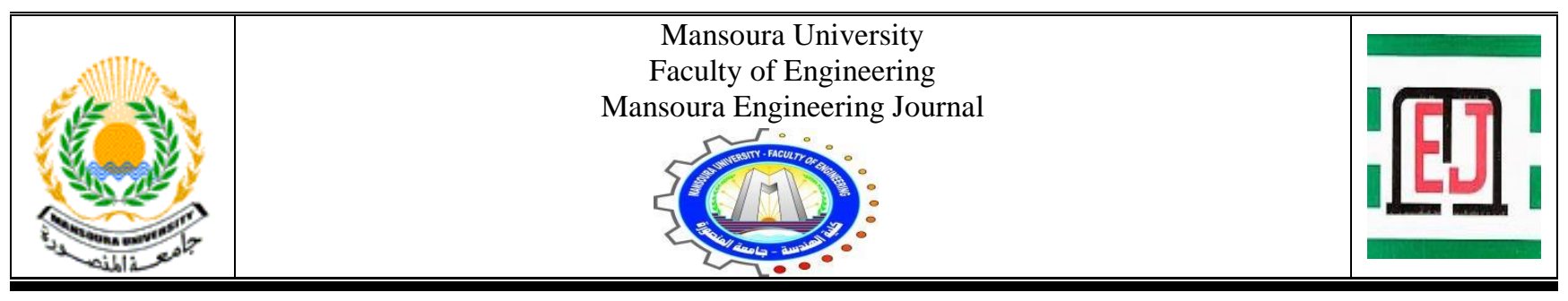

\title{
Comparative Study of Hot Asphalt Mixtures Properties Designed by Marshall and Superpave Methods
}

\begin{tabular}{|l|}
\hline KEYWORDS: \\
Marshall, \\
Superpave, \\
Rutting, \\
Fatigue, \\
Dynamic Modulus, \\
Flow Number \\
Marshall Stability, \\
Aggregate Gradation. \\
\\
\end{tabular}

\author{
Tarek Ghonemi Ibrahim Kassab
}

\section{INTRODUCTION}

$\mathrm{T}$ THE purpose of any asphalt mix design method is to determine the optimum asphalt content relevant to the designed aggregate structure to achieve its specifications requirements. There is a need to enhance the commonly used Marshall Mix design method in order to increase the lifespan of the roads. This need led the highway engineers to come up with a solution to improve the rutting

Received: (13 June, 2021) - Revised: (26 September, 2021) - Accepted: (26 September, 2021)

Corresponding Author: Tarek Ghonemi Ibrahim Kassab, Lieutenant-Colonel Staff Officer at the Egyptian Armed Forces, researcher at Works Department, Faculty of Engineering, Ain Shams university, (e- mail: Tarekghonemi@yahoo.com). and fatigue resistances to increase the lifespan of the roads. The solution is to develop the Super Performance Pavements (Superpave) mix design by Strategic Highway Research Program (SHRP). Superpave surpasses the Marshall Mix design method in many factors such as material characterization, precision in its calculations and compaction method which simulates the real compaction conditions applied on the road. Superpave was initially developed by the Strategic Highway Research Program (SHRP) (1987-1993) and it continues to improve. This method was mainly developed to improve previous HMA design methods. Some of the primary goals of this method are to achieve better incorporation of traffic and climatic conditions, better Asphalt binder and aggregate evaluation and selection, better volumetric approaches to mix design and the unique feature of the Superpave system is that it is a performance-based 
specification. The tests and analysis have direct relationships to field performance [1]. But due to its expensiveness, time consuming process and unavailability of its machines in Egypt, the Marshall Mix design method was used in this study along with some performance tests from the Superpave method. This hybrid process was done in order to find a relationship between the different performance tests found in Marshall and Superpave mix design methods to make it easier for the contractors to have an indication for the predicted performance of the mixture on site. Moreover, the hybridization extends to applying the aggregate graduation requirements in the Superpave method into the Marshall Mix design method to determine its effect on the mix properties.

Research Problem : lies in the poor performance of the roads in Egypt having pavement life much shorter than the expected. This poor performance can be attributed to the shortcomings of the Marshall Mix design method such as neglecting the actual field conditions and not representing the loads applied on the real pavement in the compaction process. On the other hand, the Superpave mix design method eliminates the previously mentioned flaws. Yet there are some limitations while trying to apply it in Egypt such as the unavailability of the required machines, the high initial cost, and the time-consuming process.

The Aim of the Research is to firstly, compare between the mixture properties designed by Marshall and Superpave methods. Secondly, determine a relation between different test methods found in Marshall and Superpave mix design methods. Thirdly, study the effect of applying the Superpave's control points and restricted zone on the aggregate gradation and the resulting mix properties in order to improve the Marshall Mix design method.

Research Importance: lies in that it contributes to finding a relation between the Marshall Stability and the Dynamic Modulus and Flow Number. This research also tries to find a hybrid method between Marshall and Superpave mix design methods to facilitate its application in Egypt.

\section{LITERATURE REVIEW}

\section{A. Marshall Mix Design Method}

This method is the most commonly used in a lot of countries due to the relatively low cost and simplicity of its procedures. The Marshall Mix design method consists of four steps: aggregate characterization, binder characterization, aggregate gradation and mix design. These steps are illustrated below

Aggregate characterization: the different aggregate physical properties are tested according to their corresponding specification.

Binder characterization: penetration grading system and viscosity grading system were used to characterize the asphalt binder to choose the right asphalt grade.

Aggregate gradation: the 3D and 4B binder gradations for the binder course and surface layer respectively were the gradations used to prepare the samples according to the Egyptian specifications [3].
Mix Design Procedures: approximately 1200gm of aggregates and filler are heated to a temperature of $175-190^{\circ} \mathrm{C}$. Bitumen is heated to a temperature of $121-125^{\circ} \mathrm{C}$ with the first trial percentage of bitumen equals ( 3.5 or $4 \%$ by weight of the mineral aggregates). The heated aggregates and bitumen are thoroughly mixed at a temperature of $150-160^{\circ} \mathrm{C}$. The mix is placed in a preheated mold and compacted by a hammer with determined blows on either side at a temperature of $138^{\circ} \mathrm{C}$ to $149^{\circ} \mathrm{C}$. The weight of mixed aggregates taken for the preparation of the specimen may be suitably altered to obtain a compacted thickness of $63.5+/-3 \mathrm{~mm}$. Four more trial mixtures are prepared with the same procedures but the bitumen content is increased by $+0.5 \%$ from the previous trial [4]. Once the specimens are prepared, their volumetric properties are then calculated.

Then these properties are plotted graphically against the asphalt content. Then the optimum asphalt content (OAC) is determined as the average value of asphalt content corresponding to maximum stability, asphalt content corresponding to maximum specific gravity and asphalt content corresponding to $4 \%$ air voids. Finally, the volumetric properties at the chosen OAC are determined and checked against the specifications limit.

\section{B. Superpave Mix Design Method}

The Superpave mix design procedure involves four steps which are selection materials that meet the super-pave specifications, selection of a design aggregate structure, Selection of the optimum asphalt content and evaluation of moisture sensitivity of the designed mixture. These steps are summarized below.

Binder Selection: the first step is to choose an asphalt binder having a Performance Grade (PG) suitable to the project location. Reference [3] proved that the PG in Egypt ranges from PG64-10 to PG76-10. Then the asphalt is tested using the Bending Beam Rheometer (BBR) and Dynamic Shear Rheometer (DSR) to determine its PG and check its suitability. The second step is to conduct the rotational viscometer test to determine the compaction and mixing temperatures through the Temperature-Viscosity chart.

Aggregate Selection : Reference [5] states that Superpave specifications divides the aggregate properties into two categories which are consensus and source properties. The source properties include the same properties tested before in the Marshall Mix design method. While the consensus properties include tests illustrated in the table (1).

TABLE 1

Aggregate Consensus Properties

\begin{tabular}{l|l}
\multicolumn{1}{c|}{ Test } & \multicolumn{1}{c}{ Specification } \\
\hline Coarse Aggregate Angularity & ASTM D 5821 \\
\hline Fine Aggregate Angularity & ASTM TP 33 \\
\hline Flat and Elongated Particles & ASTM D 4791 \\
\hline Sand Equivalent & AASHTO T 176
\end{tabular}

Design of Aggregate Structure: at least three trial blends are established by combining the gradations of the individual materials into a single blend. The blend is then compared to 
the Superpave requirements of aggregate gradation. These specifications are selected based on the maximum nominal size of the blend. The first specification is designated as control points which are certain limits at each sieve where the design curve should lie between them. The second specification is called the restricted zone. This restricted zone is an area where the design curve must not pass through. Table (2) illustrates the control points and restricted zones of the maximum nominal size $(25 \mathrm{~mm})$ used in the study.

TABLE 2

SUPERPAVE CONTROL POINTS \& RESTRICTED ZONE

\begin{tabular}{l|l|l|l|l}
\multicolumn{1}{c|}{ Sieve No } & \multicolumn{2}{c|}{ Control Points } & \multicolumn{2}{c}{ Restricted Zone } \\
\hline$I^{\prime \prime}$ & 90 & 100 & - & - \\
\hline $3 / 4{ }^{\prime \prime}$ & - & 90 & - & - \\
\hline $1 / 2{ }^{\prime \prime}$ & - & - & - & - \\
\hline $3 / 8^{\prime \prime}$ & - & - & - & - \\
\hline No. 4 & - & - & 39.5 & 39.5 \\
\hline No. 8 & 19 & 45 & 26.8 & 30.8 \\
\hline No. 16 & - & - & 18.1 & 24.1 \\
\hline No. 30 & - & - & 13.6 & 17.6 \\
\hline No. 50 & - & - & 11.4 & 11.4 \\
\hline No. 100 & - & - & - & - \\
\hline No. 200 & 1 & 7 & - & -
\end{tabular}

Then these trial blends are compacted at (5\%) asphalt content using the gyratory compactor to $\left(\mathrm{N}_{\text {Design }}=100\right)$. Afterward, the volumetric properties of the specimens of each blend are determined and used to calculate the theoretical $\mathrm{OAC}\left(\mathrm{Pb}_{\mathrm{e}}\right)$ corresponding to $4 \%$ air voids. Also, the expected volumetric properties associated with the theoretical OAC are calculated. Then the best blend is chosen based on which theoretical OAC meets the Superpave criteria.

Determining $O A C$ : after selecting the design blend and its $\left(\mathrm{Pb}_{\mathrm{e}}\right)$ is calculated, specimens with asphalt contents equal to $\mathrm{Pb}_{\mathrm{e}}, 0.5 \%$ below $\mathrm{Pb}_{\mathrm{e}}, 0.5 \%$ above $\mathrm{Pb}_{\mathrm{e}}, 1 \%$ above $\mathrm{Pb}_{\mathrm{e}}$ are prepared and compacted to $\left(\mathrm{N}_{\text {Des }}\right)$ and their volumetric properties are calculated. These volumetric properties are plotted against asphalt content to determine the optimum asphalt binder content which corresponds to $4 \%$ air voids at $\mathrm{N}_{\text {Des. }}$. Also, the other mixture volumetric properties associated with the chosen OAC are checked against the Superpave limits to verify that they meet the criteria. Finally, if all the mixture properties meet its criteria, two specimens are prepared at the chosen OAC and compacted to a number of gyrations equals to $\left(\mathrm{N}_{\mathrm{Max}}=160\right)$ to determine \% Gmm @ NMax which should be less than $(98 \%)$.

Evaluation of Moisture Sensitivity: Reference [6] illustrates the specifications and steps required to be performed on the design aggregate structure at the chosen optimum asphalt content. Six specimens are compacted to approximately $7.0 \%( \pm 1.0 \%)$ air voids by trial and error. The specimens are divided into two subsets with three specimens each. The first subset is called the unconditioned subset. On the other hand, the other subset is called the conditioned subset. These subsets are treated as mentioned in specifications. Finally, the moisture sensitivity is determined as a ratio of the tensile strengths of the conditioned subset divided by the tensile strengths of the unconditioned subset. The tensile strength ratio must be higher than $80 \%$.
Dynamic Modulus: the dynamic modulus ( $\left.\mathrm{E}^{*}\right)$ represents the stiffness of the asphalt material when tested in a compressive repeated load test. The dynamic modulus is one of the key parameters used to evaluate both rutting and fatigue cracking failures and to determine which mixture is better. The test procedures are done in accordance with specifications [7]. It includes applying repeated load on the test specimens at different temperatures $\left(4.4{ }^{\circ} \mathrm{C}, 21.1{ }^{\circ} \mathrm{C}, 37.8{ }^{\circ} \mathrm{C}\right.$, and $\left.54.4{ }^{\circ} \mathrm{C}\right)$ and different frequencies $(25 \mathrm{~Hz}, 10 \mathrm{~Hz}, 5 \mathrm{~Hz}, 1 \mathrm{~Hz}, 0.5 \mathrm{~Hz}$, and $0.1 \mathrm{~Hz}$ ). Then a dynamic modulus master curve is drawn which represents the relation between the dynamic modulus and the reduced frequency. From the master curve of each mixture specimen, an indication of fatigue resistance and rutting resistance can be determined as shown in figure (1). The mix with a higher curve on the left side of the point of intersection has better rutting resistance. While on the right side of the point of intersection, the mix with the lower curve has better fatigue resistance.

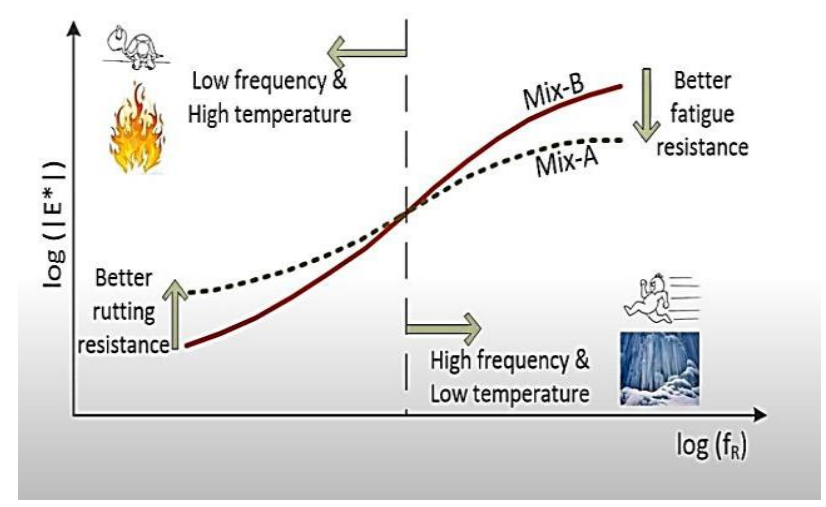

Figure 1: Dynamic Modulus Master Curve

Flow Number: is an empirical way of characterizing a hotmix asphalt (HMA) mixture's rutting potential. In the flow number test, permanent strain at each cycle is measured while constant deviator stress is applied at each load cycle on the test sample. Then a relation between cumulative permanent strain and the number of loading cycles is drawn. Permanent deformation of asphalt pavements has three zones as shown in figure (2). This test is conducted in accordance with the specifications [8].

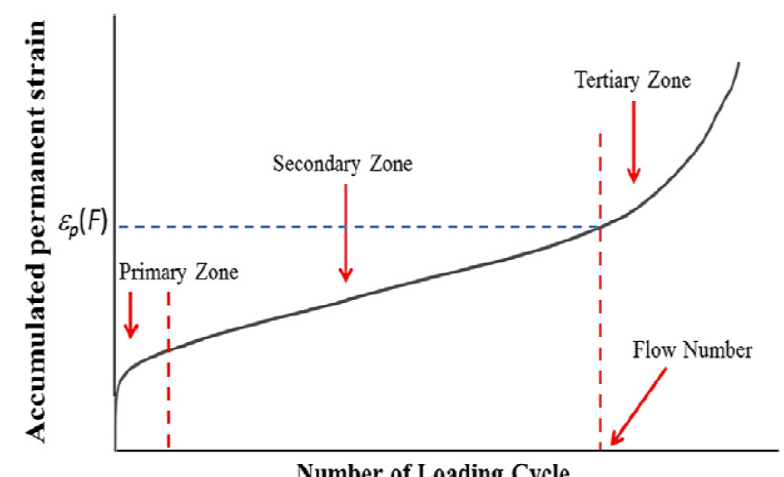

Figure 2: Flow Number Curve 


\section{StUdy Methodology}

\section{A-Marshall Mix Design}

Binder Course Samples: the 3D gradation was used to prepare these samples (B1 \& B2) according to the Egyptian specifications as shown in figure (3).

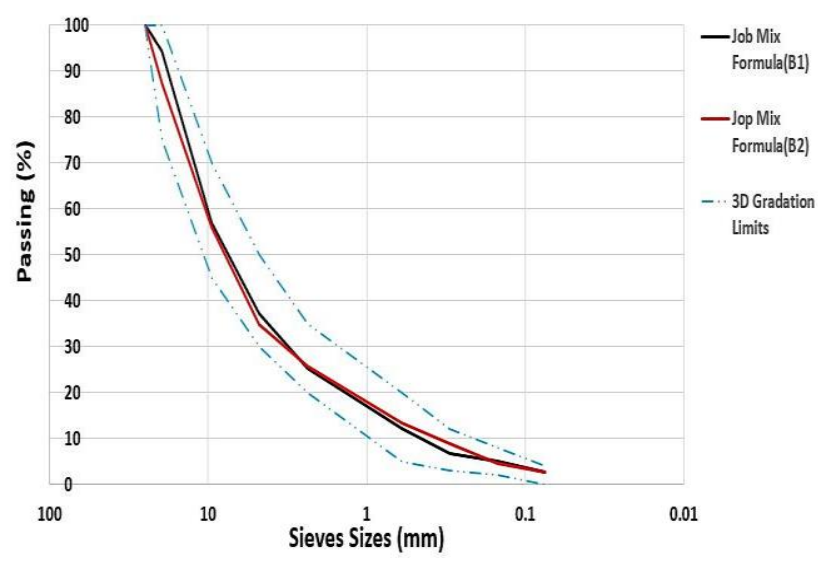

Figure3: Aggregate Gradation for Mix (B1 \&B2)

Table (3) summarizes the Volumetric Properties at OAC

TABLE 3

Volumetric Properties OF MiXTures (B1 \& B2)

\begin{tabular}{|c|c|c|c|c|}
\hline \multirow{2}{*}{ Mix Property } & \multirow{2}{*}{ B1 } & \multirow{2}{*}{ B2 } & \multicolumn{2}{|c|}{ Specifications } \\
\hline & & & Pin & $\overline{\mathrm{Max}}$ \\
\hline$\overline{\text { Optimum Asphalt Content }}$ & $4.8 \%$ & $4.6 \%$ & - & \\
\hline Unit Weight $(\mathrm{gm} / \mathrm{cm} 3)$ & 2.327 & 2.276 & - & \\
\hline $\begin{array}{l}\text { Theoretical Maximum } \\
\text { Density }(\mathrm{gm} / \mathrm{cm} 3)\end{array}$ & 2.463 & 2.421 & - & \\
\hline Air Voids (\%) & 5.5 & 6 & 3 & 8 \\
\hline Stability ( $\mathrm{kg}$ ) & 1090 & 1150 & 1000 & \\
\hline Flow $(\mathrm{mm})$ & 2.93 & 2.71 & 2 & 4 \\
\hline $\begin{array}{l}\text { Voids in Mineral } \\
\text { Aggregate } \%)\end{array}$ & 15.3 & 16.2 & 15 & \\
\hline $\begin{array}{l}\text { Voids Filled with } \\
\text { Asphalt }(\%)\end{array}$ & 64 & 62.9 & 60 & 75 \\
\hline
\end{tabular}

Surface Layer Samples: the 4B gradation was used to prepare these samples (S1 \& S2) according to the Egyptian specifications as shown in figure (4).

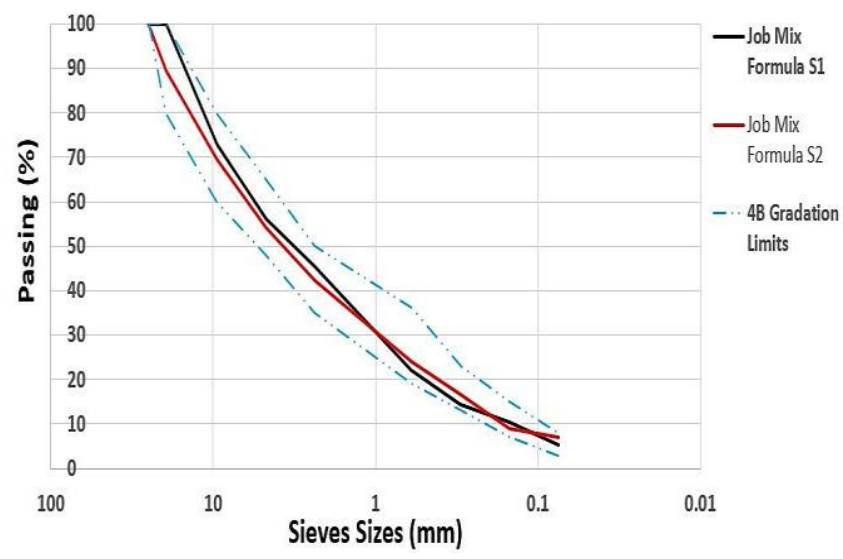

Figure 4: Aggregate Gradation for Mix (S1 \& S2)
Table (4) summarizes the Volumetric Properties at OAC

TABLE 4

VOLUMETRIC PROPERTIES OF MIXTURES (S1 \& S2)

\begin{tabular}{|c|c|c|c|c|}
\hline \multirow{2}{*}{ Mix Property } & \multirow{2}{*}{ S1 } & \multirow{2}{*}{ S2 } & \multicolumn{2}{|c|}{ Specifications } \\
\hline & & & 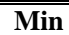 & Max \\
\hline Optimum Asphalt Content & $5.45 \%$ & $4.9 \%$ & - & \\
\hline Unit Weight $(\mathrm{gm} / \mathrm{cm} 3)$ & 2.356 & 2.326 & - & \\
\hline $\begin{array}{l}\text { Theoretical Maximum } \\
\text { Density }(\mathrm{gm} / \mathrm{cm} 3)\end{array}$ & 2.454 & 2.422 & - & \\
\hline Air Voids (\%) & 4 & 4 & 3 & 5 \\
\hline Stability $(\mathrm{kg})$ & 1284 & 1275 & 1200 & \\
\hline Flow $(\mathrm{mm})$ & 2.92 & 2.94 & 2 & 4 \\
\hline $\begin{array}{l}\text { Voids in Mineral } \\
\text { Aggregate (\%) }\end{array}$ & 15.5 & 15.9 & 15 & \\
\hline $\begin{array}{l}\text { Voids Filled with Asphalt } \\
(\%)\end{array}$ & 74 & 74.8 & 60 & 75 \\
\hline
\end{tabular}

\section{B-Dynamic Modulus Master Curve}

Figure (5) shows the relation between dynamic modulus and loading frequency for mixture B1.

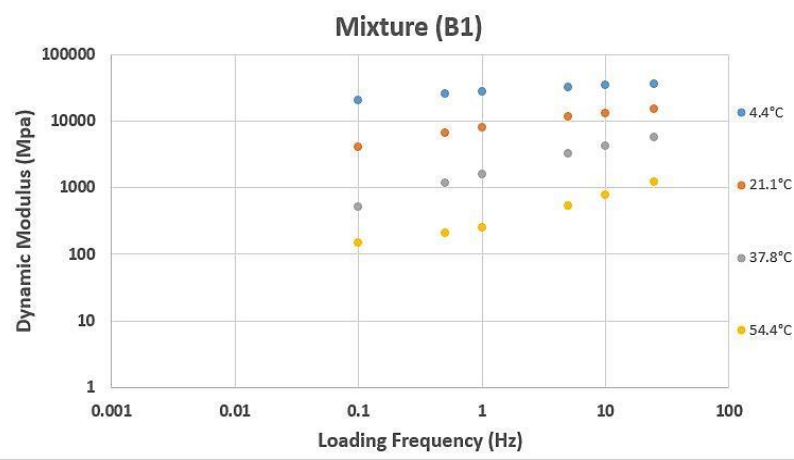

Figure 5: Dynamic Modulus Graph of Mix (B1) Before Shifting

Figure (6) illustrates the master curve for mixture B1

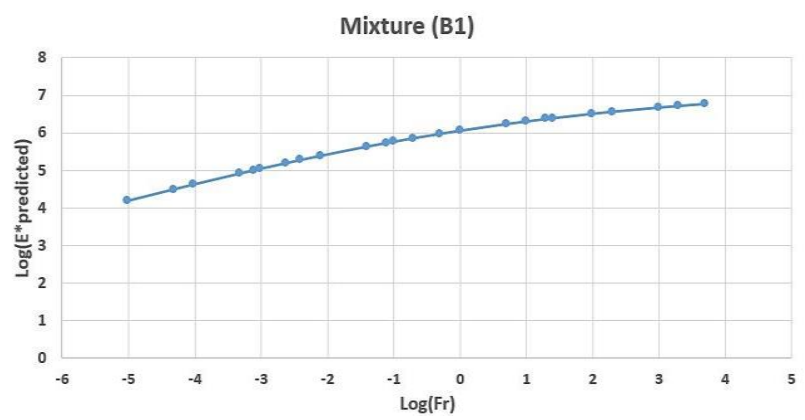

Figure 6: Dynamic Modulus Master Curve of Mix (B1)

Figure (7) shows the relation between dynamic modulus and loading frequency for mixture B2.

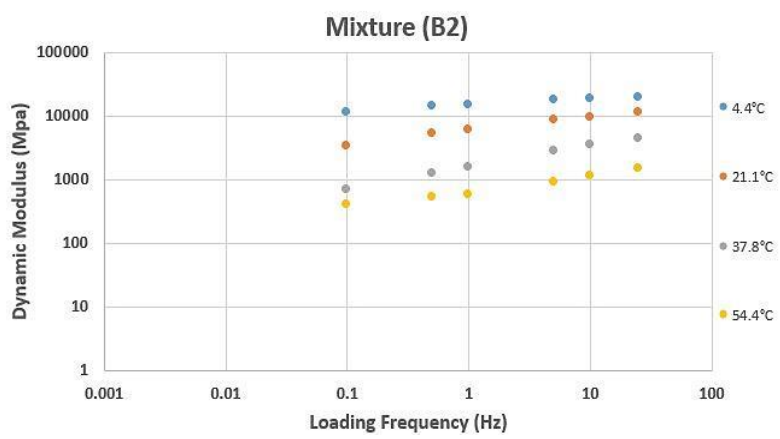

Figure 7: Dynamic Modulus Graph of Mix (B2) Before Shifting 
Figure (8) illustrates the master curve for mixture B2.

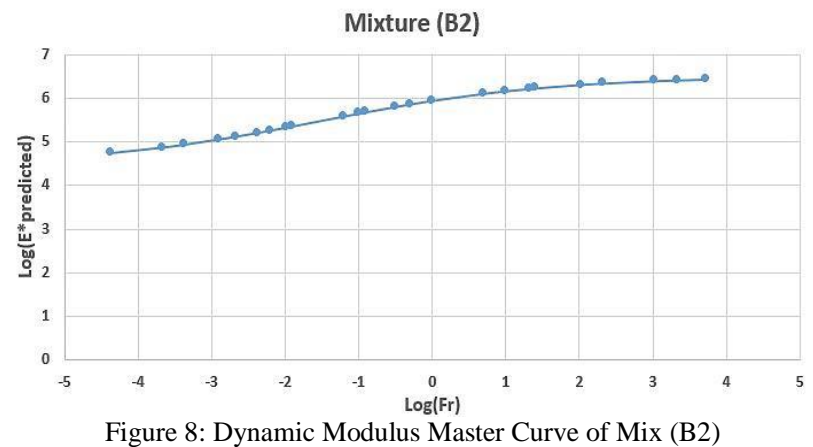

Figure (9) shows the relation between dynamic modulus and loading frequency for mixture S1.

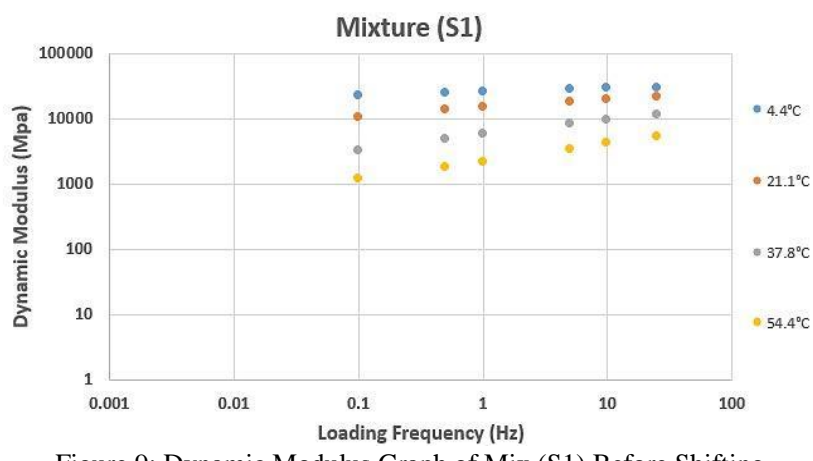

Figure 9: Dynamic Modulus Graph of Mix (S1) Before Shifting

Figure (10) illustrates the master curve for mixture S1

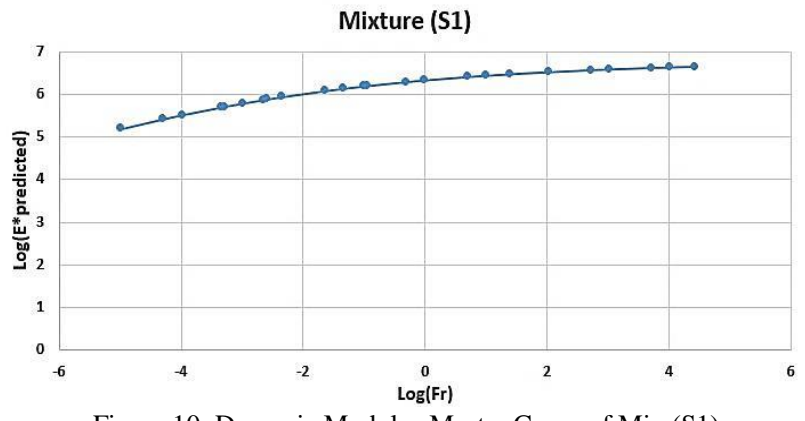

Figure 10: Dynamic Modulus Master Curve of Mix (S1)

Figure (11) shows the relation between dynamic modulus and loading frequency for mixture $\mathrm{S} 2$.

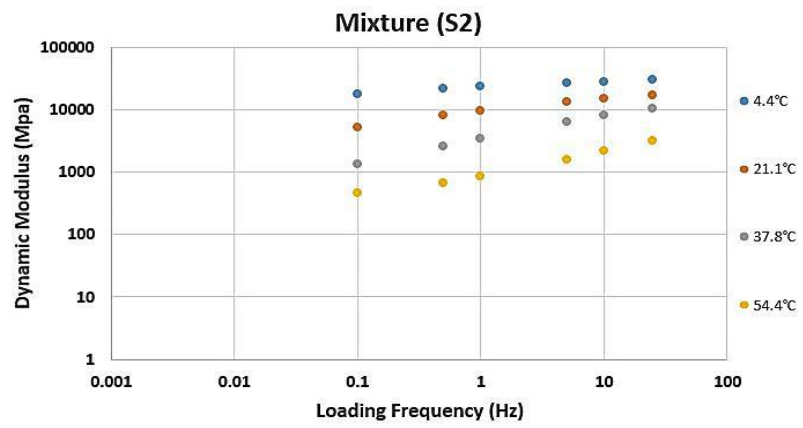

Figure 11: Dynamic Modulus Graph of Mix (S2) Before Shifting
Figure (12) illustrates the master curve for mixture S2

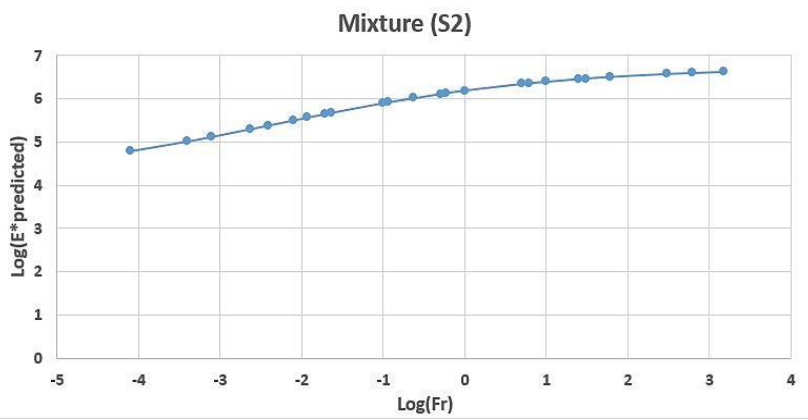

Figure 12: Dynamic Modulus Master Curve of Mix (S2)

\section{C- Flow Number}

Figure (13) shows a relation between cumulative permanent strain obtained from (AMPT) and a number of cycles for mixture B1 which was found to be (280) and mixture B2 which was found to be (496).

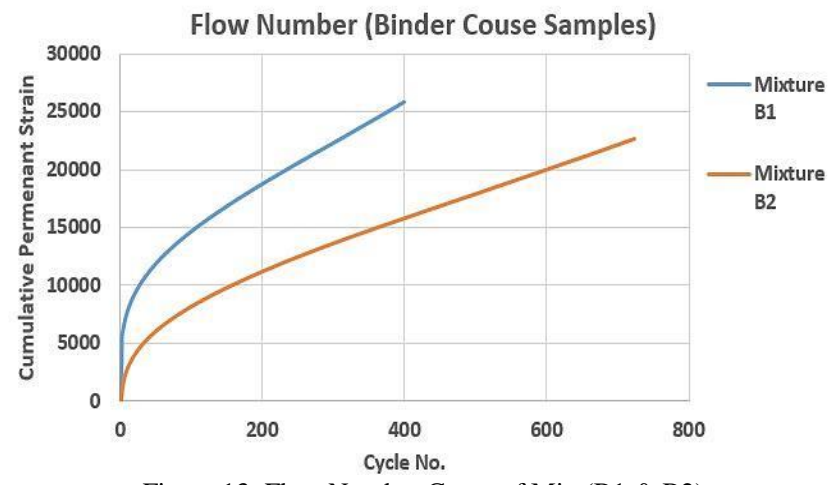

Figure 13: Flow Number Curve of Mix (B1 \& B2)

Figure (14) shows a relation between cumulative permanent strain which obtained from (AMPT) and a number of cycles for mixture S1 which was found to be (1301) and mixture S2 which was found to be (1210).

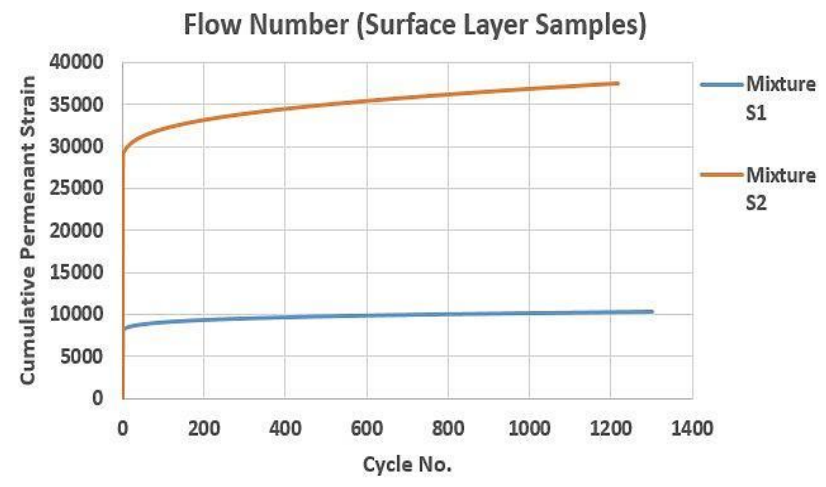

Figure 14: Flow Number Curve of Mix (S1)

\section{D- Superpave Mix Design}

The design was made as a binder course using the same aggregate gradation as sample (B2). 


\section{(1) Binder Selection}

Performance grade: Reference [3] divided the projects in Egypt into two main categories. The high scale projects (with a reliability of more than $98 \%$ ) have their performance grades ranging between PG64-10 and PG76-10. While the lower scale projects (with reliability of more than 50\%) have their performance grades ranging from PG52-10 to PG76-10.

Tests Required for Mixture Design _ as previously mentioned, the rotational viscometer test was used to determine the compaction and mixing temperature ranges.

\section{(2) Aggregate Selection}

The aggregate properties are divided into two groups as follows:

Source Properties: the aggregates used are the same as sample (B2).

Consensus Properties: table (5) summarizes the consensus properties for $\left(\mathrm{B}_{\text {new }}\right)$

TABLE 5

CONSENSUS PROPERTIES OF MiXTURE ( $\mathrm{B}_{\text {NEW }}$ )

\begin{tabular}{l|l|l|l}
\multirow{2}{*}{\multicolumn{1}{c|}{ Property }} & \multirow{2}{*}{ Value } & \multicolumn{2}{c}{ Specifications } \\
\cline { 3 - 4 } & & Min & Max \\
\hline $\begin{array}{l}\text { Coarse Aggregate } \\
\text { Angularity }(\%)\end{array}$ & 63 & 60 & \\
\hline $\begin{array}{l}\text { Fine Aggregate } \\
\text { Angularity (\%) }\end{array}$ & 51 & 45 & \\
\hline Sand Equivalent (\%) & 49 & 45 & \\
\hline Flat and Elongated (\%) & 9 & & 10
\end{tabular}

\section{(3) Design of Aggregate Structure}

The used aggregate gradation was similar to sample (B2). This gradation was compared to the Superpave control points and restricted zone as shown in figure (15).

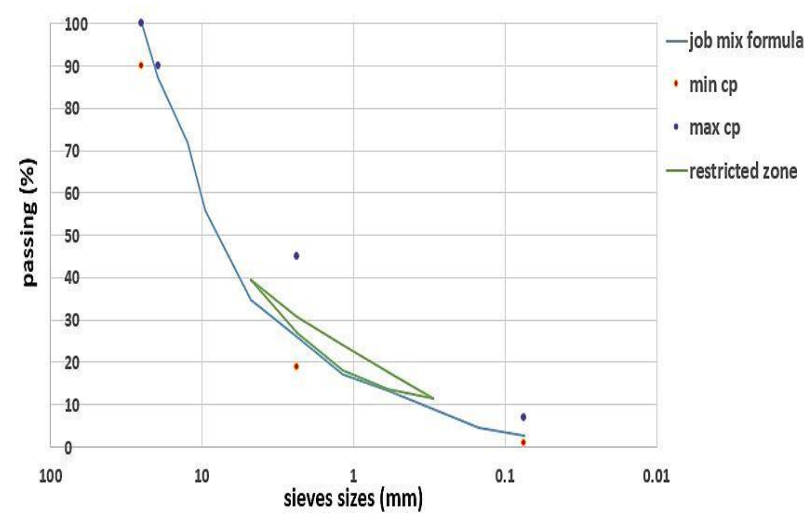

Figure 15: Aggregate Gradation of Superpave Sample (BNew)

\section{(4) Mix Design Procedures}

Initial Blend: Three samples were prepared using the aggregate gradation with the chosen initial asphalt content $\left(\mathrm{P}_{\mathrm{bi}}\right)$ which was $5 \%$. Then the samples were compacted using the Superpave Gyratory Compactor to a number of gyration
$\left(\mathrm{N}_{\text {des }}\right)$. Theoretical maximum specific gravity $\left(\mathrm{G}_{\mathrm{mm}}\right)$ [9] and bulk specific gravity $\left(\mathrm{G}_{\mathrm{mb}}\right)[10]$ were calculated for each of the three samples and used to determine their volumetric properties as shown in table (6).

TABLE 6

VOLUMETRIC PROPERTIES FOR INITIAL BLEND

\begin{tabular}{l|l}
\multicolumn{1}{c|}{ Mix Property } & \multicolumn{1}{|c}{ Value } \\
\hline Average Bulk Specific Gravity $\left(G_{m b}\right)$ & 2.387 \\
\hline Theoretical Maximum Specific Gravity $\left(G_{m m}\right)$ & 2.4679 \\
\hline Aggregate Bulk Specific Gravity $\left(G_{s b}\right)$ & 2.616 \\
\hline Initial Asphalt Content $\left(P_{b i}\right)$ & $5 \%$ \\
\hline Air Voids & $3.283 \%$ \\
\hline Voids in Mineral Aggregate & 13.32 \\
\hline Voids Filled with Asphalt & 75.35 \\
\hline$\% G_{m m} @ N_{\text {Ini }}$ & $88.038 \%$
\end{tabular}

Then the theoretical optimum asphalt content (corresponding to $4 \%$ air voids) was found to be $(4.71 \%)$. And mix volumetric properties (corresponding to $4 \%$ air void) were calculated as shown in table (7) and checked that they satisfy the Superpave limits [3].

TABLE 7

ESTIMATED VOLUMETRIC PROPERTIES

\begin{tabular}{l|l|l|l}
\multirow{2}{*}{\multicolumn{1}{c|}{ Property }} & \multicolumn{2}{|c|}{ Value } & \multicolumn{2}{|c}{ Specifications } \\
\cline { 3 - 4 } & & Min & Max \\
\hline $\begin{array}{l}\text { Estimated Optimum Asphalt } \\
\text { Content (Pbe) }\end{array}$ & $4.71 \%$ & & \\
\hline $\begin{array}{l}\text { Estimated Voids in Mineral } \\
\text { Aggregates(VMAe) }\end{array}$ & 13.39 & 12 & 14 \\
\hline $\begin{array}{l}\text { Estimated Voids Filled with } \\
\text { Asphalt(VFAe) }\end{array}$ & 70.13 & 65 & 75 \\
\hline \%Gmm @ NIni & 87.321 & - & 89
\end{tabular}

Determining Optimum Asphalt Content: Two samples were prepared for asphalt contents equal $0.5 \%$ below OAC (A), Theoretical OAC (B), $0.5 \%$ above OAC (C) and $1 \%$ above OAC (D). Each sample was compacted to the same number of gyrations as the initial blend and their properties are as follows.

Sample (A): the mix volumetric properties of sample (A) were determined as in shown in table (8).

TABLE 8

SAMPLE (A) VOLUMETRIC PROPERTIES

\begin{tabular}{l|l}
\multicolumn{1}{c|}{ Property } & \multicolumn{1}{c}{ Specification } \\
\hline $\begin{array}{l}\text { Theoretical Maximum Specific } \\
\text { Gravity }\left(G_{m m}\right)\end{array}$ & 2.4712 \\
\hline Asphalt Content $(P b)$ & $4.21 \%$ \\
\hline $\begin{array}{l}\text { Average Bulk Specific Gravity } \\
\left(G_{m b}\right)\end{array}$ & 2.362 \\
\hline Air Voids & $4.432 \%$ \\
\hline $\begin{array}{l}\text { Voids in Mineral Aggregates } \\
\text { (VMA })\end{array}$ & 13.52 \\
\hline Voids Filled with Asphalt $($ VFA $)$ & 67.23 \\
\hline \%Gmm @ Nini & 88.209
\end{tabular}

Sample (B): the mix volumetric properties of sample (B) were determined as shown in table (9). 
TABLE 9

SAMPle (B) VOlumetric Properties

\begin{tabular}{l|l}
\multicolumn{1}{c|}{ Property } & \multicolumn{1}{c}{ Specification } \\
\hline $\begin{array}{l}\text { Theoretical Maximum Specific } \\
\text { Gravity }\left(G_{m m}\right)\end{array}$ & 2.4676 \\
\hline Asphalt Content $(P b)$ & $4.71 \%$ \\
\hline $\begin{array}{l}\text { Average Bulk Specific Gravity } \\
\left(G_{m b}\right)\end{array}$ & 2.368 \\
\hline Air Voids & $4.04 \%$ \\
\hline $\begin{array}{l}\text { Voids in Mineral Aggregates } \\
\text { (VMA })\end{array}$ & 13.75 \\
\hline Voids Filled with Asphalt $($ VFA $)$ & 70.59 \\
\hline \%Gmm @ NIni & 88.805
\end{tabular}

Sample $(C)$ : the mix volumetric properties of sample $(\mathrm{C})$ were determined as shown in table (10).

TABLE 10

SAMPLE (C) VOLUMETRIC PROPERTIES

\begin{tabular}{l|l}
\multicolumn{1}{c|}{ Property } & \multicolumn{1}{|c}{ Specification } \\
\hline $\begin{array}{l}\text { Theoretical Maximum Specific } \\
\text { Gravity }\left(G_{m m}\right)\end{array}$ & 2.4334 \\
\hline Asphalt Content $(P b)$ & $5.21 \%$ \\
\hline $\begin{array}{l}\text { Average Bulk Specific Gravity } \\
\left(G_{m b}\right)\end{array}$ & 2.3708 \\
\hline Air Voids & $2.57 \%$ \\
\hline $\begin{array}{l}\text { Voids in Mineral Aggregates } \\
(\text { VMA })\end{array}$ & 14.09 \\
\hline Voids Filled with Asphalt $($ VFA $)$ & 81.74 \\
\hline$\%$ Gmm @ NIni & 89.648
\end{tabular}

Sample $(D)$ : the mix volumetric properties of sample (D) were determined as in shown in table (11).

TABLE 11

SAMPle (D) Volumetric Properties

\begin{tabular}{l|l}
\multicolumn{1}{c|}{ Property } & \multicolumn{1}{|c}{ Specification } \\
\hline $\begin{array}{l}\text { Theoretical Maximum Specific } \\
\text { Gravity }\left(G_{m m}\right)\end{array}$ & 2.4094 \\
\hline Asphalt Content $(P b)$ & $5.71 \%$ \\
\hline $\begin{array}{l}\text { Average Bulk Specific Gravity } \\
\left(G_{m b}\right)\end{array}$ & 2.3737 \\
\hline Air Voids & $1.48 \%$ \\
\hline $\begin{array}{l}\text { Voids in Mineral Aggregates } \\
\text { (VMA) }\end{array}$ & 14.44 \\
\hline Voids Filled with Asphalt $($ VFA $)$ & 89.72 \\
\hline$\%$ Gmm @ NIni & 89.950
\end{tabular}

Then a relation between asphalt content and air voids was drawn as shown in figure (16) to determine optimum asphalt content (corresponding to $4 \%$ air voids). The optimum asphalt content is found to be $(4.713 \%)$.

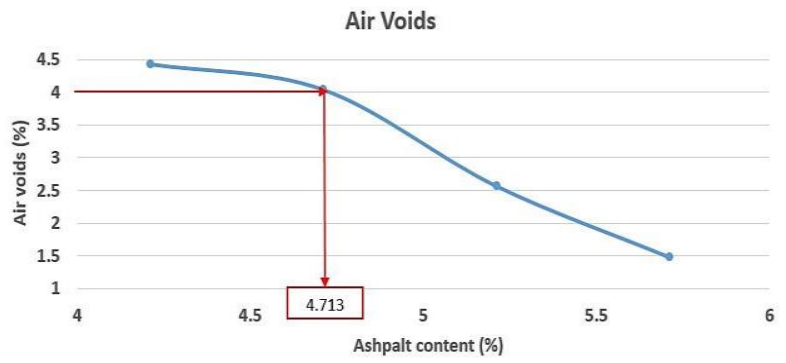

Figure 16: Air Voids versus Asphalt Content
The volumetric properties were then determined at the chosen OAC and checked in accordance with the limits of the specifications as shown in table (12).

TABLE 12

VOLUMETRIC PROPERTIES AT OAC

\begin{tabular}{l|l|l|l}
\multirow{2}{*}{ Property } & \multirow{2}{*}{ Value } & \multicolumn{2}{c}{ Specifications } \\
\cline { 3 - 4 } & & Min & Max \\
\hline $\begin{array}{l}\text { Optimum Asphalt Content } \\
\left(P_{b}\right)\end{array}$ & $4.713 \%$ & & - \\
\hline $\begin{array}{l}\text { Expected Voids in Mineral } \\
\text { Aggregates (VMA) }\end{array}$ & 13.75 & 12 & 14 \\
\hline $\begin{array}{l}\text { Expected Voids Filled with } \\
\text { Asphalt }(\text { VFA })\end{array}$ & 70.59 & 65 & 75 \\
\hline$\% G_{m m} @ N_{I n i}$ & 88.05 & - & 89
\end{tabular}

Finally, two samples at optimum asphalt content (4.713\%) were compacted. Each sample was compacted to a number of gyrations equal to $\mathrm{N}_{\text {Max }}$. After the samples were compacted to $\left(\mathrm{N}_{\text {Max }}\right)$, the bulk specific gravity $(\mathrm{Gmb})$ test was performed it was found to be (2.352). Then percentage $\% \mathrm{G}_{\mathrm{mm}}$ was calculated (95.314\%) and checked in accordance with the specification's limits $(<=98 \%)$.

\section{(5) Evaluation of Moisture Sensitivity}

Unconditioned Samples: the samples were designated as (M.D 1, M.D 2 and M.D 3). And they were treated as mentioned in specifications [6]. The test results are illustrated below in table (13).

TABLE 13

UNCONDITIONED SAMPLES CALCULATIONS

\begin{tabular}{l|l|l|l}
\multicolumn{1}{c|}{ Sample No. } & \multicolumn{1}{c}{ M.D 1 } & M.D 2 & M.D 3 \\
\hline Diameter $(\mathrm{mm})$ & 150 & 150 & 150 \\
\hline Thickness $(\mathrm{mm})$ & 60 & 60 & 60 \\
\hline WDry $(\mathrm{A})$ & 2271.67 & 2258.33 & 2135.67 \\
\hline WSub & 1317.00 & 1296.67 & 1226.33 \\
\hline WSSD & 2304.67 & 2272.67 & 2158.33 \\
\hline Gmb & 2.30 & 2.32 & 2.29 \\
\hline Gauge Reading & 323 & 278 & 230 \\
\hline Load $(\mathrm{kg})$ & 788.93 & 679.13 & 561.20 \\
\hline Load $(\mathrm{N})$ & 7731.55 & 6655.51 & 5499.76 \\
\hline Tensile Strength (KPa) & 543.872 & 470.780 & 389.028 \\
\hline Average Tensile Strength $(\mathrm{KPa})$ & & 467.89 &
\end{tabular}

Conditioned Samples: the samples were designated as (M.W 1, M.W 2 and M.W 3). And they were conditioned by vacuum saturation and warm-water soaking cycle as mentioned in specifications [6]. The test results are illustrated below in table (14). 
TABLE 14

CONDITIONED SAMPLES CALCULATIONS

\begin{tabular}{l|l||l|l}
\multicolumn{1}{c|}{ Sample No. } & M.W 1 & \multicolumn{1}{c}{ M.W 2 } & M.W 3 \\
\hline Diameter $(\mathrm{mm})$ & 150 & 150 & 150 \\
\hline Thickness $(\mathrm{mm})$ & 57 & 59 & 58 \\
\hline WDry $(\mathrm{A})$ & 2311 & 2384 & 2107 \\
\hline WSub & 1339 & 1380 & 1184 \\
\hline WSSD & 2322 & 2394 & 2141 \\
\hline Gmb & 2.352 & 2.351 & 2.202 \\
\hline Air Void Percent $(\mathrm{Pa})$ & 4.667 & 4.689 & 10.738 \\
\hline Bulk Volume $(\mathrm{E})$ & 982.67 & 1013.67 & 957.00 \\
\hline Volume of Air Void $(\mathrm{Va})$ & 45.87 & 47.53 & 102.76 \\
\hline WSSD After Partial Vacuum $\left(\mathrm{B}^{\prime}\right)$ & 2344.3 & 2418.0 & 2181.7 \\
\hline Volume of Absorbed Water $\left(\mathrm{j}^{\prime}\right)$ & 33.33 & 34.33 & 74.33 \\
\hline Degree of Saturation $\left(\mathrm{S}^{\prime}\right)$ & 72.68 & 72.23 & 72.34 \\
\hline Specification $(70-80)$ & $\mathrm{satisfy}$ & satisfy & satisfy \\
\hline Gauge Reading & 128 & 142 & 35 \\
\hline Load $($ kg) & 313 & 346 & 85.4 \\
\hline Corrected Load $(\mathrm{N})$ & 3068.71 & 3387.53 & 836.92 \\
\hline Tensile Strength $(\mathrm{KPa})$ & 228.40 & 243.58 & 61.22 \\
\hline Average Tensile Strength $(\mathrm{KPa})$ & \multicolumn{1}{|c}{177.73} & \\
\hline
\end{tabular}

Finally, the tensile strength ratio is calculated (37.99\%). And it was checked in accordance with its specification's limits (> $80 \%)$.

\section{E-Marshall Stability \& Flow}

After the Superpave design was completed and the OAC was determined, a new sample was compacted using the gyratory compactor to $\left(\mathrm{N}_{\mathrm{Max}}=160\right)$ in order to be tested by the Marshall Stability and Flow device [11]. And the results are illustrated in table (15)

TABLE 15

MARShall Stability AND Flow OF SUPERPAVE SAMPLE

\begin{tabular}{l|l}
\multicolumn{1}{c|}{ Diameter $(\mathbf{m m})$} & \multicolumn{1}{c}{$\mathbf{1 5 0}$} \\
\hline Thickness $(\mathrm{mm})$ & 55 \\
\hline WDry $(\mathrm{Kg})$ & 2410 \\
\hline WSub $(\mathrm{Kg})$ & 1400 \\
\hline WSSD $(\mathrm{Kg})$ & 2416 \\
\hline Gmb & 2.372 \\
\hline Gauge Reading & 420 \\
\hline Stability $(\mathrm{kg})$ & 1281 \\
\hline Flow $(\mathrm{mm})$ & 4.112
\end{tabular}

\section{Analysis Of The Results}

\section{A. Dynamic modulus for Marshall Mixtures}

Binder Course: the comparison between binder course samples is done using dynamic modulus to determine which mix is better in terms of rutting and fatigue resistance. As shown in figure (17) B2 has better rutting resistance than B1 since B2 is higher on the left side of the curve because, in low frequencies and high temperatures, mixture B2 has lower strain than B1 so it has higher dynamic modulus values. Also, it has better fatigue resistance than $\mathrm{B} 1$ since $\mathrm{B} 2$ is lower on the right side of the curve because, in high frequencies and low temperatures, mixture B2 has higher strain than B1 so it has lower dynamic modulus values.

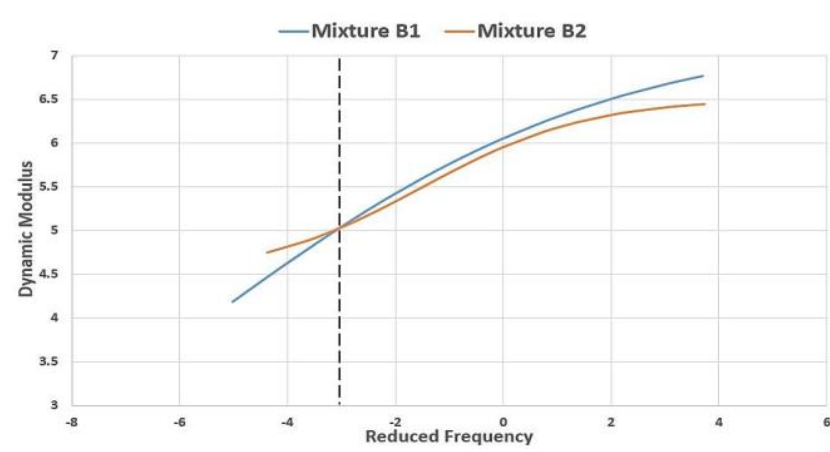

Figure 17: Dynamic Modulus Master Curves of Binder Course Samples

As previously noted, B2 is found to have higher stability $(1150 \mathrm{Kg})$ than B1 $(1090 \mathrm{Kg})$.

Surface Layer: the comparison between surface layer samples is done using dynamic modulus to determine which mix is better in terms of rutting and fatigue resistance. As shown in figure (18) S1 has better rutting resistance than S2 since $\mathrm{S} 1$ is higher on the left side of the curve because, in low frequencies and high temperatures, mixture $\mathrm{S} 1$ has lower strain than S2 so it has higher dynamic modulus values. Also, it has better fatigue resistance than $\mathrm{S} 2$ since $\mathrm{S} 1$ is lower on the right side of the curve because, in high frequencies and low temperatures, mixture S1 has higher strain than S2 so it has lower dynamic modulus values.

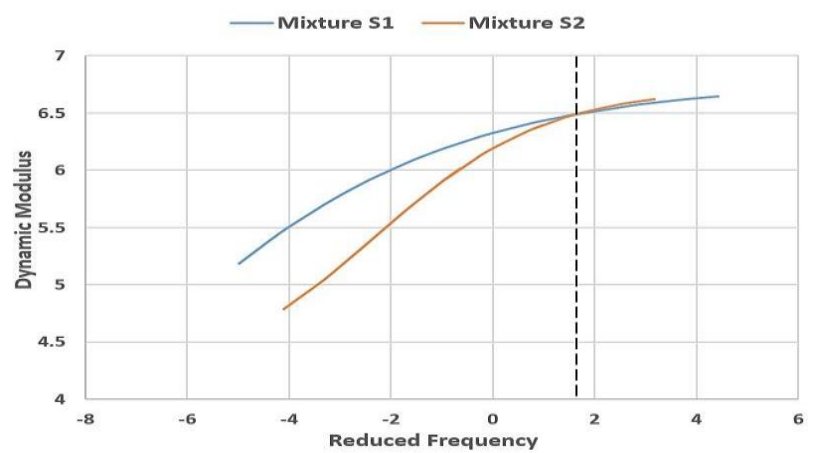

Figure 18: Dynamic Modulus Master Curves of Surface Layer Samples

As illustrated before, $\mathrm{S} 1$ is found to have higher stability $(1284 \mathrm{Kg})$ than $\mathrm{S} 2(1275 \mathrm{Kg})$.

From the previous results, it is obvious that the sample with higher stability has better dynamic modulus results therefore it has better fatigue and rutting resistance.

\section{B. Flow number for Marshall Mixtures}

Binder Course: the comparison between binder course samples is done using flow number to determine which mix is better in terms of rutting resistance. The FN results for the two binder course samples were as follows:

Mixture B2 has flow number (496) and mixture B1 has flow number (280). This means that the tertiary zone of B2, where the drastic shear failure of the mix occurs, appears at a higher number of cycles than B1. Therefore, Mixture B2 has higher rutting resistance than mixture B1. And as previously 
noted, mixture $\mathrm{B} 2$ has the stability of $(1150 \mathrm{~kg})$ and mixture B1 has the stability of $(1090 \mathrm{~kg})$.

Surface Layer: the comparison between surface layer samples is done using flow number to determine which mix is better in terms of rutting resistance. The FN results for the two surface layer samples were as follows:

Mixture S1 has flow number (1301) and mixture S2 has flow number (1210). This means that the tertiary zone of S1, where the drastic shear failure of the mix occurs, appears at a higher number of cycles than S2. Therefore Mixture S1 has a higher rutting resistance than mixture S2. And as previously noted, mixture $\mathrm{S} 1$ has a stability of $(1284 \mathrm{~kg})$ and mixture $\mathrm{S} 2$ has a stability of $(1275 \mathrm{~kg})$.

From the previous results, it is obvious that the sample with higher stability has a higher flow number which indicates that it has better rutting resistance.

\section{Stability and Flow for Superpave Mixture}

The Superpave sample $\left(\mathrm{B}_{\mathrm{New}}\right)$ and the Marshall sample (B2) were compared using their stability and flow results to determine which mix design method produces a better mixture in terms of rutting and fatigue resistance. Sample $\left(\mathrm{B}_{\mathrm{New}}\right)$ has stability $=1281 \mathrm{~kg}$ and flow $=4.112 \mathrm{~mm}$. Sample (B2) has stability $=1150 \mathrm{~kg}$ and flow of sample $(\mathrm{B} 2)=2.71 \mathrm{~mm}$. From the previous data, it is clear that the sample designed using the Superpave method $\left(\mathrm{B}_{\mathrm{New}}\right)$ has a higher stability than the one designed using the Marshall Mix design method (B2). This means that $\left(\mathrm{B}_{\mathrm{New}}\right)$ indicates a better rutting and fatigue resistance than (B2) although they share the same aggregate gradation.

\section{Alternative Methodology}

\section{A. Overview}

In this chapter, the effect of mix factors on the results was studied in order to achieve better results. The factor investigated in this study was the aggregate gradation. An alternative design methodology was developed by applying the Superpave's control points and restricted zone on the gradation used in the Marshall Mix design method. In the following sections, the effect of the gradation will be discussed in both the binder course and surface layer.

\section{B. Binder Course}

Superpave control points and restricted zone were applied to the previous binder course samples in this study. For example, the gradation of the sample (B1) met the Superpave specifications easily as shown in figure (19). Moreover, previous researches have proven that 3D Binder gradation usually used in the Marshall Mix design method fits easily into the Superpave control points therefore there is no need to change the gradation when designing the Binder Course.

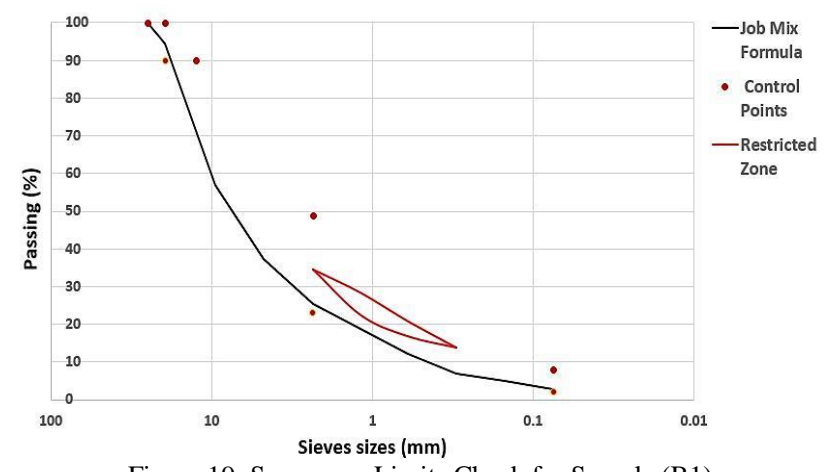

Figure 19: Superpave Limits Check for Sample (B1)

\section{Surface Layer}

As for the surface layer, it was found that the limits of the 4B gradation, which is used in in this study and usually used in the Marshall Mix design method, do not meet the control points and restricted zone of the Superpave method. Therefore, a modified gradation was used as shown in table (16) [3].

TABLE 16 MODIFIED 4B GRADATION

\begin{tabular}{l||l|l}
\multicolumn{1}{c}{ Sieve Size } & \multicolumn{2}{c}{ Modified 4B Gradation } \\
\cline { 2 - 3 } & \multicolumn{1}{c}{ Min } & \multicolumn{1}{c}{ Max } \\
\hline$l^{\prime \prime}$ & 100 & 100 \\
\hline $3 / 4^{\prime \prime}$ & 100 & 100 \\
\hline $1 / 2^{\prime \prime}$ & 80 & 87 \\
\hline $3 / 8^{\prime \prime}$ & 70 & 80 \\
\hline No. 4 & 50 & 65 \\
\hline No. 8 & 30 & 46 \\
\hline No. 16 & 20 & 39 \\
\hline No. 30 & 15 & 30 \\
\hline No. 50 & 13 & 22 \\
\hline No. 100 & 8 & 17 \\
\hline No. 200 & 3 & 6
\end{tabular}

Then a new aggregate gradation was designed for sample $\left(\mathrm{S}_{\mathrm{New}}\right)$ in accordance with the modified gradation limits as shown in figure (20).

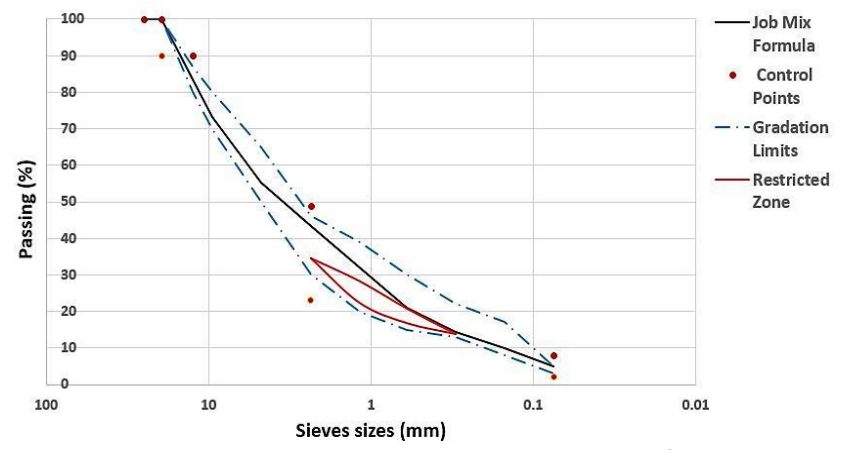

Figure 20: Superpave Limits Check for Sample $\left(S_{\text {New }}\right)$

Then the mixture was designed using the Marshall Mix design method following the same steps mentioned before to produce a sample designated as $\left(\mathrm{S}_{\mathrm{New}}\right)$. The OAC was found to be $5.4 \%$ for $\operatorname{mix}\left(\mathrm{S}_{\mathrm{New}}\right)$. Then the mixture volumetric properties are checked with the specification's limits in accordance with the Egyptian specifications as shown in table (17) 
TABLE 17

Volumetric Properties Of MiXture $\left(\mathrm{S}_{\mathrm{New}}\right)$

\begin{tabular}{|c|c|c|c|c|}
\hline \multirow{2}{*}{ Mix Property } & \multirow{2}{*}{ Value } & \multicolumn{2}{|c|}{ Specifications } & \multirow{2}{*}{ State } \\
\hline & & Min & Max & \\
\hline Optimum Asphalt Content & $5.4 \%$ & - & & \\
\hline Unit Weight $(\mathrm{gm} / \mathrm{cm} 3)$ & 2.349 & F & & \\
\hline $\begin{array}{l}\text { Theoretical Maximum } \\
\text { Density }(\mathrm{gm} / \mathrm{cm} 3)\end{array}$ & 2.446 & & & \\
\hline Air Voids (\%) & 4 & 3 & 5 & Passed \\
\hline Stability $(\mathrm{kg})$ & 1314 & 1200 & & Passed \\
\hline Flow $(\mathrm{mm})$ & 2.96 & 2 & 4 & Passed \\
\hline $\begin{array}{l}\text { Voids in Mineral } \\
\text { Aggregate }(\%)\end{array}$ & 15.35 & 15 & & Passed \\
\hline $\begin{array}{l}\text { Voids Filled with } \\
\text { Asphalt }(\%)\end{array}$ & 73.6 & 60 & 75 & Passed \\
\hline
\end{tabular}

From the previous results, the stability of $S_{\text {New }}(1314 \mathrm{~kg})$ is found to be higher than the previous samples although they are made from the same materials. This increase in stability can be attributed to the new aggregate structure and gradation which are designed to meet the Superpave's control points and restricted zone. And as mentioned before, the higher stability gives an indication of better dynamic modulus and flow number results. This also gives an indication of better rutting and fatigue resistances.

\section{COnClusion, RECommendation \& Future RESEARCH}

\section{A. Conclusion}

In the end, as a conclusion to what was discussed in the previous chapters. When trying to prepare the samples for this study, it was found that although the Superpave method takes into consideration many factors that simulate the natural conditions besides the traffic loading which results in better rutting and fatigue resistance. But it has huge limitations in Egypt as it is not yet very popular in Egypt. This resulted in a sort of unavailability of the machines required in this particular mix design method, therefore, making the production process very expensive. Moreover, the technicians in Egypt are not so acquainted with the Superpave method which makes them consume more time than usual to prepare just one sample. On the other hand, the Marshall Mix design method is much cheaper and commonly used in Egypt which makes it easier for the contractors to use it in their projects despite having other limitations such as not taking the climatic conditions into consideration. It was proven in this study that the Superpave method produces a mixture that has higher stability than that designed using Marshall Method which means higher rutting and fatigue resistance. Moreover, the aforementioned Superpave limitations extend to its performance tests. Making it difficult and costly to use tests such as Dynamic Modulus and Flow Number when comparing two or more mixtures. That's why this study tries to find a relation between the results from Dynamic Modulus and Flow Number tests with the results from Marshall Stability which is well known in Egypt. The results show that stability results are directly proportional with both Dynamic Modulus and Flow Number results. This means that higher stability gives an indication of better rutting and fatigue resistance. But it must be taken into consideration that the Superpave performance tests simulate the actual traffic loading applied on the pavement in the field thus giving more accurate results. Also, this relation is considered empirical and a numerical relation couldn't be determined as the dynamic modulus has several values at each temperature-frequency combination obtained from performing the test. Also, the flow number value is obtained from the test only.

Finally, the effect of the aggregate gradation requirements used in the Superpave method on the results was studied by applying these requirements to the Marshall Mix design method. It was found that this new gradation system helped increase the stability of the mix while keeping the stiffness between the limits of the specifications, thus, improving rutting and fatigue resistance of the mixture.

\section{B. Recommendation}

After what has been discussed in this study, it is recommended to apply the Superpave control points and restricted zone on the aggregate gradation when designing a surface layer using Marshall Mix design method as it will result in better stability, thus, better fatigue and rutting resistance. On the other hand, this recommendation can be put aside while designing a binder course using the Marshall Mix design method as it fits easily between the control points and doesn't pass through the restricted zone.

\section{Future Research}

To complement the work of this study, additional research can be conducted to determine an equation that relates the Marshall Stability results with the results of the Dynamic Modulus and Flow Number tests numerically. Also, further research can be performed to determine the effects of the mix factors other than aggregate gradation on Marshall Stability. Moreover, further studies can be done to determine a way that can make the Egyptian asphalt pass the moisture sensitivity.

\section{REFERENCES}

[1] M. M. E. Zumrawi \& S. A. Sheikh Edrees, "Comparison of Marshall and Superpave asphalt design methods for Sudan pavement mixes", International Journal of Scientific and Technical Advancements, Volume 2, Issue 1, pp. 29-35, 2016.

[2] Transportation Research Board of the National Academies, "A Manual for Design of Hot Mix Asphalt with Commentary", NCHRP Report 673, 2011.

[3] S. Khedr, M. Saudy, M. Khafagy, R. Abdelaziz, M. Magdy, \& Y. Boraay. "Superpave application in Egypt", Egypt, 2010.

[4] I. F. Jasim, "Comparison between Marshall and Superpave Mixtures Design”, Al-Qadisiya Jour nal For Engineering Sciences, Vol. 5, No. 4, 394-406, 2012.

[5] J. P. Zaniewski, "Comparison of $19 \mathrm{~mm}$ Superpave and Marshall Base II Mixes in West Virginia", Department of Civil and Environmental Engineering, West Virginia, 2003.

[6] Standard Method of Test for Resistance of Compacted Asphalt Mixtures to Moisture-Induced Damage, AASHTO T 283

[7] Standard practice for developing dynamic modulus master curves for asphalt mixtures, AASHTO R 62 
[8] Standard Method of Test for Determining the Dynamic Modulus and Flow Number for Asphalt Mixtures Using the Asphalt Mixture Performance Tester (AMPT), AASHTO - TP 79

[9] Theoretical Maximum Specific Gravity (Gmm) and Density of Asphalt Mixtures, AASHTO T 209

[10] Bulk Specific Gravity of Compacted Bituminous Mixtures Using Saturated Surface-Dry Specimens, AASHTO T 166

[11] Resistance to Plastic Flow of Bituminous Mixtures Using Marshall Apparatus, AASHTO T 245

[12] E. Ray Brown, S. Prithvi, Kandhal, Jingna Zhang, "performance testing for hot mix asphalt", NCAT report 01-05, 2001.

[13] Asphalt Institute, Superpave series no.2 (sp-2), Third edition, 2001.

[14] Standard method of test for determining dynamic modulus of Hot Mix Asphalt (HMA), AASHTO TP 62. 2007

[15] M. R. Islam, S. A. Kalevela, \& G. Mendel, g. (2019) "How the mix factors affect the dynamic modulus of hot-mix" asphalt. Journal of composites science, 3, 3-72.

[16] M. R. Islam, S. A. Kalevela, \& S. K. Nesselhauf, "Sensitivity of the flow number to mix factors of hot-mix asphalt". Infrastructures, 4(2), 2019.

[17] J. Zhang, A. E. Alvarez, S. I. Lee, A. Torres, \& L. F. Walubita, "Comparison of flow number, dynamic modulus, and repeated load tests for evaluation of HMA permanent deformation". Construction and building materials, 44, 391-398, 2013.

[18] T. Harman, J. D'Angelo \& J. Bukowski, "Superpave Asphalt Mixture Design Workshop", U.S Department of Transportation, Federal Highway Administration, 2002
Title Arabic:

دراسة مقارنة لخصائص الظليط الأسفلتي المصمم بطريقتي مارشال وسوبربيف

\section{Arabic Abstract:}

طريقة تصميم سوبربيف تأخذ في اعتبارها العديد من العوامل التى تحاكي الظروف

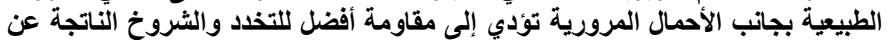

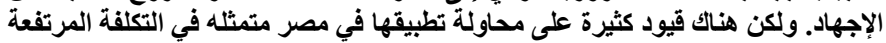

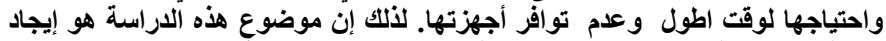

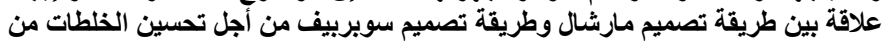

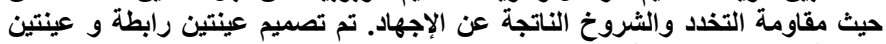

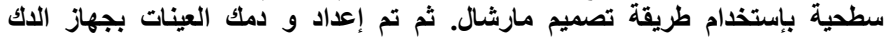

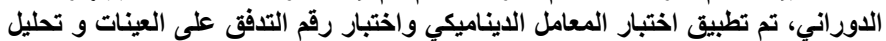

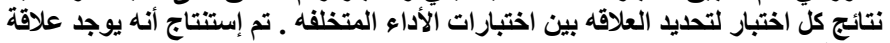

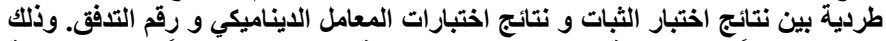

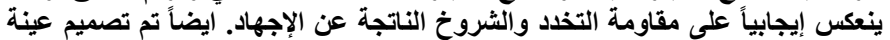

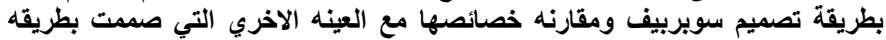

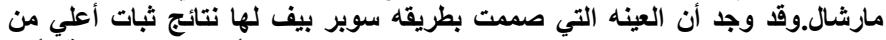

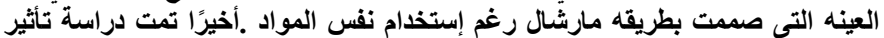

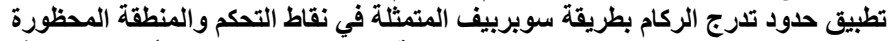

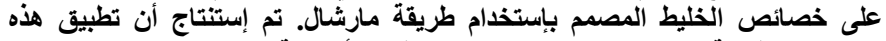
الحدود مع طريقة مارشال يحسن خصائص الخلطات الأسفلتية. 